\title{
PROGESTIN-INDUCED PSEUDOHERMAPHRODITISM IN THE FEMALE HAMSTER
}

\author{
A. J. VOMACHKA, D. G. PAUP,* L. P. CONIGLIO, \\ M. J. MaMANUS AND L. G. GLEMENS \\ Hormones and Behavior Laboratory, Department of Zoology, \\ $5 A$ Biology Research Center, Michigan State University, \\ East Lansing, Michigan 48823, U.S.A.
}

(Received 16th April 1973)

\begin{abstract}
Summary. The synthetic progestins, norethynodrel and norethindrone, given neonatally to female hamsters caused masculinization of the genitalia, increased masculine sexual behaviour in the adults, and reduced spontaneous and hormone-induced female sexual behaviour. Neonatal progesterone treatment did not masculinize female hamsters but diminished hormone-induced feminine behaviour. Dydrogesterone neither masculinized nor defeminized female hamsters.
\end{abstract}

\section{INTRODUCTION}

Administration of synthetic progestins to women during pregnancy can cause morphological as well as behavioural masculinization of female offspring (Wilkins, Jones, Holman \& Stempfel, 1958; Wilkins, 1960; Erhardt \& Money, 1967). A similar syndrome is also seen as a result of exposure to prenatal androgens produced by virilizing ovarian tumours in the mother, or in cases of adrenal hyperplasia of the fetus (adrenogenital syndrome) (Bongiovanni \& McPadden, 1960). This adrenogenital syndrome has also been reported to lead to some cases of aberrant sexual behaviour (lesbianism) as well as morphological virilization (Ehrhardt, Epstein \& Money, 1968; Ehrhardt, Evers \& Money, 1968).

In order to create a behavioural syndrome in the laboratory which could serve as a model for experimental studies of progestin-induced pseudohermaphroditism, immature female golden hamsters were treated with progestins and the effects on their adult sexual behaviour were tested. In the normal hamster, there is a marked sexual dimorphism of adult sexual behaviour. The male sexual behaviour pattern, which consists of mounting the female, achieving several pelvic thrusts and dismounting, seldom occurs in normal adult female hamsters, or in those ovariectomized and given testosterone propionate (TP) (Eaton, 1970; Carter, Clemens \& Hoekema, 1972). The characteristic behaviour pattern of a sexually receptive female is one of assuming a rigid lordosis

* Present address: Department of Health, George Washington University, Washington D.G., U.S.A. 
posture in the presence of the male. During lordosis, there is a concave arching of the back which allows the male vaginal access. This posture is maintained while the male mounts and dismounts. The adult castrated male will display a lordosis pattern in response to treatment with ovarian hormones, though this response is of shorter duration than that of the normal female (Eaton, 1970; Tiefer \& Johnson, 1971; Carter et al., 1972).

\section{MATERIALS AND METHODS}

Animals

Female golden hamsters born in the Hormones and Behavior Laboratory at Michigan State University were used as experimental subjects. Animals were weaned at 21 days of age and housed in groups of two to four and five to seven in cages with dimensions of $7 \times 10 \times 6$ in. and $8 \times 17 \times 6$ in., respectively. Colony conditions were maintained at constant temperature and humidity with a reversed day-night light cycle of $14 \mathrm{hr}$ light, $10 \mathrm{hr}$ dark with lights off at 11.00 hours. Food and water were freely available.

\section{Treatment}

Experimental animals were injected daily with $100 \mu \mathrm{g}$ progesterone, dydro-

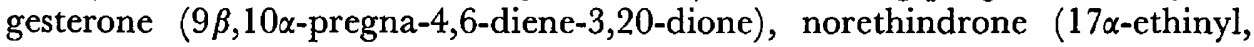
19-nortestosterone), or norethynodrel (17 $\alpha$-ethynyl-17-hydroxy-5(10)-estren-3one) on Days 2, 3 and 4 of life (the day of birth was taken as Day 1). Each progestin was dissolved in sesame oil, $100 \mu \mathrm{g} / 0.03 \mathrm{ml}$. Puncture sites, at the time of injection, were sealed with flexible collodion and all animals were inspected for leakage before being returned to their mothers.

Control animals were injected on Days 2, 3 and 4 of life with the vehicle and were tested for all behavioural measures concurrently. While scores from these animals were used for comparison in this study, the results of their tests have been reported in detail elsewhere (Coniglio, Paup \& Clemens, 1973). Behavioural testing began 2 to $3 \mathrm{hr}$ after the lights were put off.

\section{Tests for oestrus}

Between 60 and 90 days of age, all animals were tested for 4 or 5 consecutive days to determine whether behavioural oestrus was evident. Tests for receptivity consisted of placing the female with a sexually vigorous male hamster in a 10 -gallon aquarium with wood shavings covering the bottom (these aquaria provided the observation arena for all behavioural testing) and observing whether the female would display lordosis in response to the male. The occurrence of lordosis was taken as a behavioural indicator of receptivity. Each test lasted $3 \mathrm{~min}$. Upon completion of receptivity tests, all animals were ovariectomized under ether anaesthesia. Ovaries were fixed in Bouin's solution, sectioned at $9 \mu \mathrm{m}$, stained with haematoxylin and eosin and examined for the presence of corpora lutea.

\section{Mounting tests}

One month after ovariectomy, all females were given a preliminary 10-min 
test for male sexual behaviour with a sexually receptive stimulus female. Stimulus female hamsters were brought into sexual receptivity with three daily injections of $12 \mu \mathrm{g}$ oestradiol benzoate (OB) followed by an injection of $500 \mu \mathrm{g}$ progesterone on Day 4, 4 to $6 \mathrm{hr}$ before the beginning of testing. On the day after the preliminary test for male sexual behaviour, all experimental females were placed on a schedule of daily injections of $300 \mu \mathrm{g}$ TP and were tested for male behaviour 7, 14, 21 and 28 days after the initiation of TP treatment.

The procedure used in mounting behaviour tests consisted of allowing each experimental female a 5-min period of adaptation to the test arena. Following adaptation, the sexually receptive stimulus female was placed in the arena for 10 min and the frequency of mounting behaviour shown by the experimental female was recorded. A mount was scored as a rear mount, head mount, or side mount depending upon the orientation of the experimental female. A rear mount consisted of clasping the flanks of the stimulus female from the rear while showing pelvic thrusting. Clasping from the head or side while showing pelvic thrusting constituted the criteria for head and side mounts, respectively. Upon completion of the male behaviour tests, TP administration was discontinued.

\section{Lordosis tests}

Experimental females were tested for female sexual behaviour in response to exogenous ovarian hormones 4 to 5 weeks after the cessation of TP injections. Experimental females were given $6 \mu \mathrm{g}$ OB daily for 3 days. On Day 4, each female was injected with $500 \mu \mathrm{g}$ progesterone 4 to $6 \mathrm{hr}$ before the beginning of testing. Females were placed in the arena with a vigorous male hamster for 10 min while lordosis frequency and duration were recorded on an Esterline-Angus event recorder. An identical test was given 2 weeks later. The data from these two lordosis tests were combined for statistical evaluation.

At the termination of the experiment, all animals were killed. Anogenital distance was measured. Clitoral bones plus cartilage were dissected from the animals and their length measured.

\section{RESULTS}

\section{Male behaviour}

The mean mount frequencies for rear, head and side mounts combined are shown in Text-fig. 1 for each 10-min test for all four hormone treatment groups. Females which received norethindrone or norethynodrel neonatally showed a highly significant increase in mounting behaviour with daily injections of TP. Analysis of variance of Day 28 mounting scores for all four groups showed a significant difference among groups $(\mathrm{F}=7.382, P<0.05)$. Animals treated with norethynodrel achieved significantly higher scores than did animals treated with norethindrone (Duncan's New Multiple Range Test, $P<0 \cdot 05$ ), but the norethindrone and dydrogesterone groups did not differ significantly from each other. Animals treated with norethindrone achieved a significantly higher frequency of mounting than the animals treated with progesterone (Duncan's $P<0.05)$. Scores for animals treated with dydrogesterone were not different from those for animals treated with progesterone and the latter were not 
different from controls injected neonatally with sesame oil (Coniglio et al., 1973).

\section{Female behaviour}

The results of the receptivity tests are given in Table 1 as the percentage of animals showing lordosis at least once during the 4 to 5 days of testing. Neonatal treatment with norethynodrel caused the greatest decrease in receptivity in the

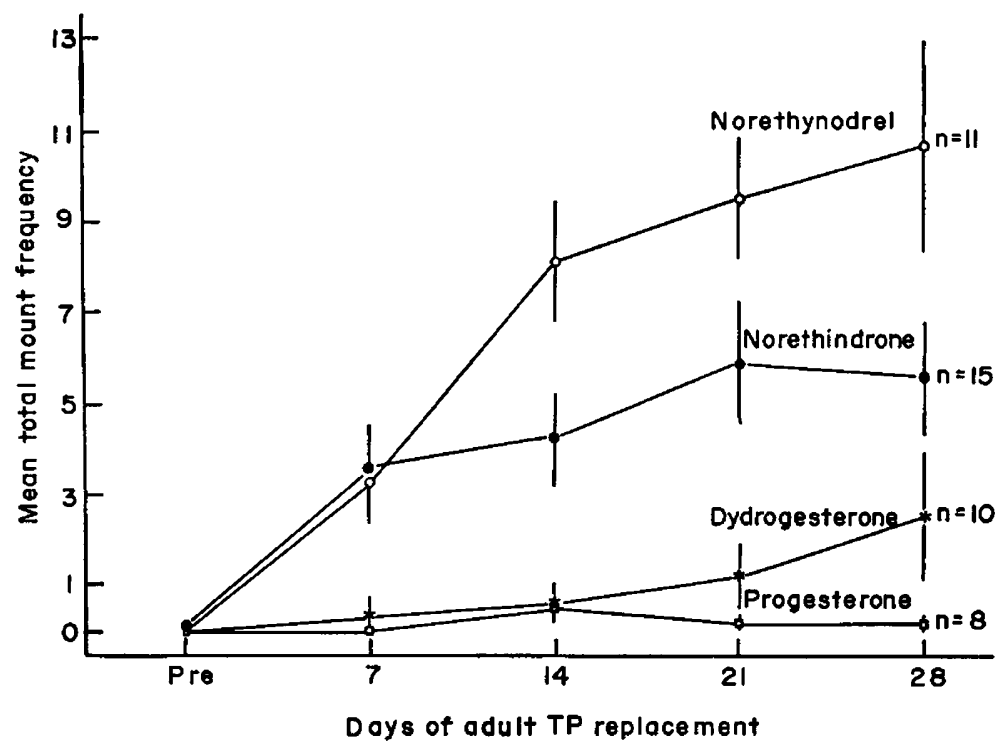

TEXT-FIG. 1. Effects of neonatal treatment with progestins on male behaviour (mounting frequency) in female hamsters.

Table 1. Peripheral morphology and reproductive physiology of female hamsters treated neonatally with progestins

\begin{tabular}{|c|c|c|c|c|c|}
\hline $\begin{array}{l}\text { Neonatal } \\
\text { treatment }\end{array}$ & $\begin{array}{c}\text { No. of } \\
\text { animals/group }\end{array}$ & $\begin{array}{c}\text { Adult } \\
\text { anogenital } \\
\text { distance } \\
(\mathrm{mm})\end{array}$ & $\begin{array}{c}\text { Adult } \\
\text { clitoral bone } \\
\text { and cartilage } \\
\text { length }(\mathrm{mm})\end{array}$ & $\begin{array}{l}\% \text { of animals } \\
\text { showing } \\
\text { receptivity }\end{array}$ & $\begin{array}{c}\% \text { of animals } \\
\text { with corpora } \\
\text { lutea }\end{array}$ \\
\hline $\begin{array}{l}\text { Progesterone } \\
\text { Dydrogesterone } \\
\text { Norethindrone } \\
\text { Norethynodrel } \\
\text { Sesame oil } \uparrow\end{array}$ & $\begin{array}{r}8 \\
10 \\
15 \\
11 \\
10\end{array}$ & $\begin{array}{l}5 \cdot 05 \pm 0.37 \\
5 \cdot 38 \pm 0.16 \\
8 \cdot 13 \pm 0.29 \\
8 \cdot 66 \pm 0.20 \\
6.69 \pm 0.31\end{array}$ & $\begin{array}{c}2.90 \pm 0.04 \\
2.87 \pm 0.04 \\
3.45 \pm 0.06 \\
3.13 \pm 0.06 \\
\square\end{array}$ & $\begin{array}{r}100 \\
90 \\
73 \\
45 \\
-\end{array}$ & $\begin{array}{c}100 \\
100 \\
100^{*} \\
91 \\
100\end{array}$ \\
\hline
\end{tabular}

intact females. While norethynodrel achieved a greater reduction of receptivity in the intact female than did norethindrone, $100 \%$ and $90 \%$, respectively, of progesterone- and dydrogesterone-treated animals were receptive at least once during the test period $\left(\chi^{2}=9 \cdot 080\right.$, d.f. $\left.=3, P<0 \cdot 05\right)$.

Mean lordosis frequency and mean lordosis duration scores following exogenous treatment with $\mathrm{OB}$ and progesterone are shown in Text-fig. 2. Both 
frequency and duration scores differed significantly among the four treatment groups ( $\mathrm{F}=22.127, P<0.001$ and $\mathrm{F}=38.069, P<0.001$, respectively).

While the hamsters treated with progesterone and dydrogesterone exhibited fewer lordosis responses, their responses were of longer duration. Comparison of lordosis scores of these groups with females given oil injections neonatally and tested under similar conditions (Coniglio et al., 1973) revealed no significant difference between dydrogesterone and control animals. The lordosis duration of the progesterone group, however, was significantly shorter than that of the
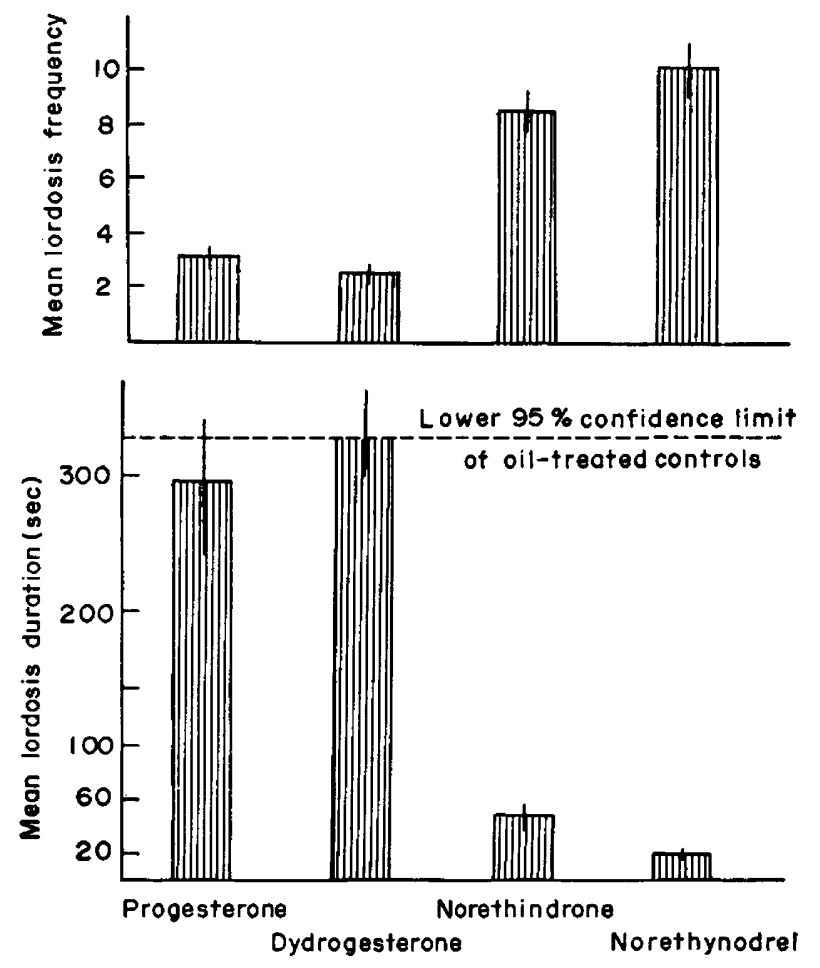

TEXT-FIG. 2. Effects of neonatal treatment with progestins on female behaviour (duration and frequency of lordosis) in female hamsters.

control animals (Duncan's, $P<0 \cdot 05$ ). Lordosis frequency scores for the dydrogesterone and progesterone groups were not different from controls. The norethynodrel and norethindrone groups showed a higher frequency and shorter duration of lordosis response than did the progesterone and dydrogesterone animals (Duncan's, $P<0.05$ and $P<0.05$ ).

\section{Morphological results}

The mean anogenital distance and the mean length of clitoral bone plus cartilage are given in Table 1 for all hormone treatment groups. Anogenital distances as well as clitoral bone and cartilage lengths differed significantly across groups in an analysis of variance $(\mathrm{F}=43.574, P<0.001$ and $\mathrm{F}=31.750$, $P<0.001$, respectively). The females in the norethynodrel and norethindrone 
groups exhibited a greater anogenital distance and a longer clitoris than the animals in the dydrogesterone and progesterone groups (Duncan's, $P<0.05$ ).

\section{Histology}

The results of histological examination of the ovaries are given in Table 1 . Corpora lutea were present in all of the animals in the progesterone, dydrogesterone, and norethindrone groups. However, eight of the fifteen animals $(53 \%)$ in the norethindrone group had ovaries with cystic follicles. No corpora lutea were observed in one of the eleven animals treated neonatally with norethynodrel. This group was ovariectomized at 60 days of age whereas the other three groups had their ovaries removed between 80 and 90 days.

\section{DISGUSSION}

Female hamsters treated neonatally with norethindrone or norethynodrel responded to TP treatment by exhibiting high levels of male sexual behaviour as compared to animals given injections of progesterone or sesame oil. Furthermore, norethindrone and norethynodrel defeminized the female hamsters by reducing the number of animals displaying sexual receptivity before ovariectomy. Following ovariectomy and treatment with exogenous $\mathrm{OB}$ and progesterone, the females treated with norethynodrel and norethindrone continued to respond differently from controls in that they displayed a high frequency, short duration pattern of lordosis. Quantitatively, this type of lordosis response pattern is similar to that typically shown by male hamsters when treated with oestrogen and progesterone (Carter et al., 1972).

The mechanism by which norethynodrel and norethindrone achieved these masculinizing and defeminizing effects is not clear. Both norethynodrel and norethindrone are 19-nortestosterone derivatives and their action may be due to their basic androgenic structure. It is well known that androgens present during the time of sexual differentiation will masculinize peripheral sex morphology and masculinize as well as defeminize sex-related behaviour patterns in many species (Bruner \& Witschi, 1946; Goldman, 1970; Davidson $\&$ Levine, 1972, for review of behaviour). In the present study, all three of these effects were manifest in animals treated with norethynodrel and norethindrone.

We cannot exclude the possibility that the behavioural masculinizing and defeminizing properties of norethynodrel could also be the result of its oestrogenlike structure. Although norethynodrel is a 19-nortestosterone derivative, it can be prepared as the reduction product of oestrone (Petrow, 1971) and its basic chemical structure is that of an 'oestren'. Recently, work in this laboratory (Paup, Coniglio \& Clemens, 1972; Coniglio et al., 1973) has shown that behavioural masculinization and defeminization can be achieved by oestrogens as well as androgens which could be aromatized to oestrogens. With regard to conversion of progestins, Ryan, Naftolin, Reddy, Flores \& Petro (1972) have also reported the aromatization in vitro of norethindrone to $17 \alpha$-ethinyl oestradiol. Similar results have been reported for conversion of norethindrone in vivo in the rabbit (Both-Miedema and his co-authors, 1972).

In contrast to these findings, Whalen, Peck \& LoPiccolo (1966) have reported 
that norethindrone caused a morphological virilization in rats but did not suppress either spontaneous sexual receptivity or sexual receptivity induced by exogenous ovarian hormones. This discrepancy may be explained in terms of basic species differences. Also, the progestins in the study by Whalen were always injected into the pregnant mother. Consequently, the amount of the hormone and its metabolites which actually reached the fetus is not known. In a recent study, Foote \& Peterson (1972) gave large doses of norethindrone and progesterone to guinea-pigs prenatally. Progesterone caused no genital or behavioural masculinization and did not cause a decrease in oestrous response. Only one of four animals became pregnant when mated, however, while all untreated controls conceived. Animals treated with norethindrone were morphologically and behaviourally masculinized but they did show oestrous cycles. Again, only one of four animals became pregnant.

Progesterone, while not causing a behavioural masculinization in the present study, did reduce the duration of lordosis in female hamsters. Since progesterone is the precursor of most steroids, there is no way of knowing from the present data whether this defeminizing effect was due to a direct action of progesterone or was the result of some metabolite.

While it is certainly too early to generalize from these results with hamsters to the situation in humans, similarities as well as differences are evident. Whereas in both species the presence of synthetic progestins at the time of sexual differentiation has a masculinizing effect both on behaviour and genital morphology, we also found a behavioural defeminizing effect of neonatal progestins in hamsters. So far such an effect has not been seen in humans (Ehrhardt \& Money, 1967). Whether this discrepancy is due to basic species differences or to the present limits of clinical assessment in evaluating subtle behavioural changes is not known. Species differences notwithstanding, the results of this study suggest a behavioural model for further assessment of progestin-induced pseudohermaphroditism.

\section{ACKNOWLEDGMENTS}

The authors wish to thank Mr M. John Dwyer for assistance in statistical analysis and Dr J. A. King for critically reading the manuscript. Oestradiol benzoate, testosterone propionate and progesterone were supplied by $\operatorname{Dr} \mathrm{P}$. L. Perlman of Schering Corp. Dydrogesterone ( $9 \beta, 10 \alpha$-pregna-4,6-diene-3,20dione) was supplied by Dr G. R. McKinney of Mead Johnson. Norethindrone (17 -ethinyl, 19-nortestosterone) was supplied by Dr G. W. Moersch of Park Davis and Co. Norethynodrel (17 $\alpha$-ethynyl-17-hydroxy-5(10)-estren-3-one) was supplied by Dr R. L. Bergstrom of G. D. Searle and Co. This research was supported by a General Research Support Grant from the Michigan State University, College of Human Medicine; USPHS Research Grant No. HD 06760-01; USPHS Training Grant No. GM 01751-01 from the National Institute of General Medical Sciences.

\section{REFERENCES}

Bongrovanni, A. M. \& McPadden, A. J. (1960) Steroids during pregnancy and possible fetal consequences. Fert. Steril. 11, 181 . 
Both-Miedema, R., van Groenstein, T. J. A., deGroot, W. G., Huis in't Veld, L. G., Rijsdjk, J. G. J. M. \& Stekelenburg, P. (1972) 19-Nortestosterone I. Its metabolism in the rabbit. Steroids Lipids Res. 3, 49.

Bruner, J. \& Witschi, E. (1946) Testosterone-induced modifications of sex development in female hamsters. Am. F. Anat. 79, 293.

Garter, C. S., Glemens, L. G. \& Hoekema, D. J. (1972) Neonatal androgen and adult sexual behavior in the golden hamster. Physiol. Behav. 9, 89.

Coniglio, L. P., Paup, D. G. \& Clemens, L. G. (1973) Hormonal specificity in the suppression of sexual receptivity of the female golden hamster. $\mathcal{7}$. Endocr. $57,55$.

Davidson, J. M. \& Levine, S. (1972) Endocrine regulation of behavior. A. Rev. Physiol. 34, 375.

EATON, G. (1970) Effect of a single prepuberal injection of testosterone propionate on adult bisexual behavior of male hamsters castrated at birth. Endocrinology, 87, 934.

Ehrhardt, A., Epstein, R. \& Money, J. (1968) Fetal androgens and female gender identity in the early-treated adrenogenital syndrome. Fohns Hopkins med. F. 122, 160.

Ehrhardt, A., Evers, K. \& Money, J. (1968) Influence of androgen and some aspects of sexually dimorphic behaviour in women with the late-treated adrenogenital syndrome. Johns Hopkins med. F. $123,115$.

Ehrhardt, A. \& Money, J. (1967) Progestin-induced hermaphroditism: IQ and psychosexual identity in a study of ten girls. F. Sex Res. 3, 83.

Foote, W. D. \& PEterson, D. W. (1972) Steroidal influence on morphology and behaviour in guineapigs. F. Reprod. Fert. 30, 469.

Goldman, A. (1970) Virilization of the external genitalia of the female rat fetus by dehydroepiandrosterone. Endocrinology, 87, 432.

Paup, D. G. Coniglio, L. P. \& Clemens, L. G. (1972) Masculinization of the female golden hamster by neonatal treatment with androgen or estrogen. Horm. \& Behav. 3, 123.

Petrow, V. (1971) Antifertility agents. In Progress in Medicinal Chemistry, Vol. 8, p. 171. Eds. G. P. Ellis and G. B. West. Butterworth, London.

Ryan, K. J., Naftolin, F., Reddy, V., Flores, F. \& Petro, Z. (1972) Estrogen formation in the brain. Am. F. Obstet. Gynec. 114, 454.

Tiefer, L. \& Johnson, W. A. (1971) Female sexual behaviour in male golden hamsters. F. Endocr. 51, 615.

Whalen, R. E., Peck, C. K. \& LoPiccolo, J. (1966) Virilization of female rats by prenatally administered progestin. Endocrinology, 78, 965.

Wilkins, L. (1960) Masculinization of female fetus due to use of orally given progestins. F. Am. med. Ass. $172,1028$.

Wilkins, L., Jones, H. W., Holman, G. H. \& Stempfel, R. S. (1958) Masculinization of the female fetus associated with administration of oral and intramuscular progestins during gestation: non-adrenal female pseudohermaphroditism. 7. clin. Endocr. Metab. 18, 559. 